\title{
N-Acetylcysteine for Chronic Obstructive Pulmonary Disease?
}

\author{
Marc H. Lavietes \\ Pulmonary and Critical Care Medicine, University Hospital, Newark, N.J., USA
}

Pela et al. [1] wrote an interesting article recommending daily oral N-acetylcysteine (NAC) as a preventive therapy for patients with chronic obstructive pulmonary disease (COPD). For three reasons, however, I do not share their enthusiasm for this therapy.

First, support for the initial premise, namely that NAC may have a beneficial effect on COPD, is equivocal. Our recent review of this topic concluded that 'evidence for efficacy is conflicting and, in general, provides minimal support for the clinical utility of $\mathrm{N}$-acetylcysteine' [2]. We interpreted at least two of the references which Pela et al. quoted as supportive of the hypothesis as being negative studies [3, 4]. The British Thoracic Society Research Committee study, for example, showed no statistical difference in the number of exacerbations between the placebo and treatment groups. Therefore, I would not have expected a positive outcome for this study.

Second, in the Pela study the control group was not offered a placebo tablet. The study group received 'standard therapy plus NAC, $600 \mathrm{mg}$ once a day' while the control group subjects received 'standard therapy' alone. How was the study presented and explained to each participant? How could study group subjects not have known that they were receiving an extra pill? Would not the study group subjects have had greater expectations than their control counterparts for their outcome because they were receiving an extra, experimental drug? This omission is critical because the outcome measures used in the Pela

\begin{tabular}{ll}
\hline KARGER & ( 1999 S. Karger AG, Basel \\
0025-7931/99/0666-0491\$17.50/0 \\
$\begin{array}{l}\text { Fax +4161306 1234 } \\
\text { E-Mail karger@karger.ch } \\
\text { www.karger.com }\end{array}$ & $\begin{array}{l}\text { Accessible online at: } \\
\text { www.karger.com/journals/res }\end{array}$
\end{tabular}

study, with the exception of spirometry, all require subjective verbal responses to questions regarding each subject's perception of his own well-being.

Third, the major end points of the study were subjective and based on the patients' responses to the questionnaires used. The questionnaires were not well designed for the assessment of interindividual differences in the subjects' perceptions of the severity of their symptoms; no details were given as to how the questionnaires were administered.

Let us consider, for example, the grading of 'mucus' and 'dyspnea' in this study. Subjects were asked to grade both mucus and dyspnea as 'unchanged', 'increased' or 'severely increased' (the greater degree of worsening of mucus was described as 'increased and purulent'). Subjects were given no opportunity to report any perceived decrease of either symptom. It is a well-known principle in the discipline of behavioral science that, to compare quantitative estimates of people's perceptions of their feelings or symptoms, the perceptive range given by the questionnaire for each symptom must be set in the same way for all individuals. This principle, developed in the work of the exercise physiologist Gunnar Borg, has been elegantly reviewed [5].

The scale used in the Pela study, which offered the subject only three choices for the grading of his dyspnea or mucus production, does not provide an optimal perceptive range for the quantification of these symptoms. Data

Marc H. Lavietes, MD

University Hospital (I 354)

Pulmonary and Critical Care Medicine

150 Bergen Street

Newark, NJ 07103-2406 (USA) 
concerning mucus and dyspnea would have been more convincing if subjects had been asked to consider a range of $0-10$ for each symptom, where 0 represented no mucus or no dyspnea and 10 represented either maximal mucus ( $\geq 2$ coffee cups of mucus per day) or maximal dyspnea (the shortness of breath you feel after running up ten flights of stairs). Given the knowledge of what both 0 and 10 represent, how would each subject then have rated his mucus or dyspnea both before and after the trial? Given the language with which subjects were asked to assess mucus and dyspnea in this trial, it would not be surprising if study subjects were less likely to report an increase in the severity of their symptoms than control subjects.

New therapy for COPD is greatly needed but I do not believe that NAC will be useful.

\section{References}

1 Pela R, Calcagni AM, Subiaco S, Isidori P, Tubaldi A, Sanguinetti CM: N-Acetylcysteine reduces the exacerbation rate in patients with moderate to severe COPD. Respiration 1999; 66:495-500.

2 Marin MG, Lavietes MH: Mucolytic agents, agents for the relief of dyspnea, and respiratory stimulants; in Cherniack NS, Altose MD, Homma I (eds): Rehabilitation of the Patient with Respiratory Disease. New York, McGraw-Hill, 1999, pp 295-299.

3 British Thoracic Society Research Committee: Oral $\mathrm{N}$-acetylcysteine and exacerbation rates with chronic bronchitis and severe airway obstruction. Thorax 1985;40:832-835.
4 Rasmussen JB, Glennon C: Reduction in days of illness after long-term treatment with $\mathrm{N}$-acetylcysteine controlled-release tablets in patients with chronic bronchitis. Eur Respir J 1988;1: 351-355.

5 Noble BJ, Robertson RJ: The Borg scale: Development, administration, and experimental use; in Perceived Exertion. Champaign, Human Kinetics, 1996, chap 3, pp 59-92. 